UDC 130.2

LBC 71.06

\title{
TOLERANCE OF THE RUSSIAN CULTURE
}

\author{
Aleksandr G. Ilyin \\ Elabuga Institute of Kazan (Volga Region) Federal University, Elabuga, Russian Federation
}

\begin{abstract}
The acute theme of this article is tolerance of the Russian culture through its meaningful manifestations in the world around us. The existence of different opinions on the concept of tolerance and inclusion of Russia into the global information society require the philosophical understanding of this concept and determination of its ontological background. The need for this understanding will help identify the ways of interaction of the Russian social reality with the outside world. The peculiarity of the process of liberal reforms in Russia also causes some resistance on the part of Russian culture and the Russian mentality. It should not be regarded as a lack of the Russian culture development, its inability to resist the onslaught of technological progress, on the contrary, this is its advantage it isn't subject to technological progress, but it subordinates it. This also concerns other spheres of life of society social, political, economic etc. Tolerance of the Russian culture is in meaningful and fair interaction with others, with their traditions and objectives. Such notions as consciousness, tolerance and emotional generosity are the basis of the Russian culture but not an anachronism. The Russian culture remains a significant guideline for researches in the contemporary informative world. A great number of world pattern answers are found in the Russian culture itself. Submissiveness and longanimity are not an indication of moral neglect and disability to understand current events. They are outstanding characteristics of the Russian culture and genuine tolerance, existing up to the present time.

Key words: Russian culture, Russian mentality, tolerance, conscience, humility, justice.
\end{abstract}

УДК 130.2

ББК 71.06

\section{ТОЛЕРАНТНОСТЬ РУССКОЙ КУЛЬТУРЫ}

\author{
Александр Геннадьевич Ильин \\ Елабужский институт Казанского (Приволжского) федерального университета, \\ г. Елабуга, Российская Федерация
}

\begin{abstract}
Аннотация. Значимость данной статьи заключается в том, что в ней рассматривается толерантность русской культуры через ее основные проявления. Наличие различных мнений по поводу понятия толерантности и последствий включения России в глобальное информационное общество требует осмысления феномена толерантности в философском контексте и определения его глубинных культурных оснований. Осуществление этого осмысления поможет определить способы взаимодействия российской социальной действительности с внешним миром. Процесс либеральных реформ в России также вызывает определенное сопротивление со стороны русской культуры и русского менталитета. Это является признаком неразвитости русской культуры, ее неспособности устоять перед натиском технического прогресса; напротив, в этом проявляется ее преимущество: она не подчиняется слепо техническому прогрессу, но подчиняет его себе. Это касается и других сфер жизни общества - социальной, политической, экономической и др. Толерантность русской культуры заключается в осмысленном и справедливом взаимодействии с Другим, с его традициями и целями.

Такие понятия, как совесть, терпимость, отзывчивость, не являются архаическим пережитком русской культуры, а составляют ее основу. В современном информационном мире русская культурная традиция дает ответы на многие вопросы мироустройства. Смирение и терпимость - это не признаки слабости и неспособности понять происходящее; напротив, эти черты русской культуры, характерные для нее и поныне, и есть главные проявления подлинной толерантности.

Ключевые слова: русская культура, русский менталитет, толерантность, совесть, смирение, справедливость.
\end{abstract}


Понятие толерантности является достаточно популярным среди политиков, социологов, психологов и, конечно же, философов, хотя в настоящее время интерес к ней несколько снизился. Толерантность - весьма неоднозначное понятие, хотя его смысл часто пытаются свести к терпимости. В данной статье мы попытаемся выявить и описать русское видение толерантности, обнаружить оттенки этого понятия, присущие русской культуре.

Толерантность, социальная изнутри, открывает двери тому, что проникает снаружи в общество. То, как происходит проникновение определенных ценностей в то или иное общество, описывает нам так называемое Окно Овертона - окно возможностей и допущений. Возможности связаны с внедрением чуждых и неприемлемых ценностей в обществе. Толерантность в этом процессе может сыграть отрицательную роль: она будет способствовать тому, что общественное сознание и сознание отдельного человека не будут оказывать сопротивление новым ценностям, привносимым извне. Россия испытывает воздействие либеральной пропаганды и внедрения либеральных демократических ценностей, начавшееся в конце 80-х - начале 90-х гг. и активно продолжающееся по сей день, «ибо толерантность стала идеологическим оружием Запада в противостоянии с Россией. Они требуют от России толерантности, снимая с себя обязательства по этому явлению» [4, c. 1080]. В этой связи интерес к русской толерантности в философии высок. Посредством анализа толерантности русской культуры и русского менталитета откроются новые аспекты данного понятия и будет дан ответ на вопрос, почему в России так трудно идут либеральные реформы и почему русский человек сопротивляется навязываемым извне благим идеям демократии и свободы.

Русский менталитет весьма противоречив, непредсказуем, но вместе с тем постоянен в рамках времени, как, собственно, и любой менталитет. О русском менталитете можно сказать, что он вневременной. Противоречивость и загадочность русского менталитета надо оценивать как его многогранность и многоуровневость. В этом случае можно не согласиться с Н.А. Бердяевым, который описывал противоречивость русского характера и русской культуры [2]. Противоречивость и проявление противоположных качеств возможны в зависимости от рассмотрения данной культуры. Если речь идет о внутренней точке зрения на русскую культуру, то противоречивость - это ответная реакция на внешние воздействия. Без этих воздействий русская культура оставалась бы в определенном постоянстве. Есть в ней то, что проявляет свою значимость с особой силой в определенное время в менталитете. В русском менталитете есть что-то вечное; русский человек живет вечными ценностями, а его долгое ожидание плодов своих благих, по-божески, что называется, поступков часто путают с леностью. Это не леность, а большая духовная работа сознания русского человека, его внутренняя напряженность. Русский осмысливает свои поступки, поступки других, пытается найти их вечную неизменную логику. Если нет этой вечной логики, ориентированной на добро, то на хорошее надеяться не стоит. Прагматизм не может быть вечным, потому как он требует все новых и новых выгод, забывая о прежних действиях, делах. Содеянное прежде, в русском менталитете, продолжает жить, оно не кончается при достижении цели и получении материального поощрения, оно перерастает в благо, а благо - это одухотворенность достигнутого.

Большую роль в формировании менталитета играют внешние факторы. Культура русского народа является стержнем его менталитета, не позволяющим полностью изменить культуру - душу народа - путем внедрения чуждых, а порой просто идущих против совести человека ценностей.

Менталитет выступает защитным буфером, сферой, оберегающей душу народа от внешних воздействий. Глубинным источником менталитета является культура, внешние факторы - это среда реализации внутренних культурных свобод. При этом внешние обстоятельства провоцируют менталитет на определенную ответную реакцию, оказывая и воздействие на культуру. Культура в этом воздействии идет на уступки внешним факторам, маскируясь менталитетом. Это смирение часто называют слабостью русской культуры, ее отсталостью от западной культуры. Русский бездействует, не берется создавать пред- 
приятие и получать прибыль из него, потому что он не смеет делать то, что не свойственно его культуре и мировоззрению. Взяв необходимое, на большее он не посягает. Именно смирение как внутренняя работа и внутренняя борьба характерны для русской культуры. «Специфическим для русского человека является то, что часто его толерантность перерастает в долготерпеливость, во всепрощенчество... Комплекс долготерпеливости... обеспечивал выживаемость в трудных условиях, устойчивость духовного мира, стабилизацию социальных отношений, помогая русскому человеку выстоять, не сломаться, и в самых сложных условиях продолжать делать свое извечное человеческое дело» $[16$, с. 4]. Именно благодаря смирению русский человек способен сохранить свою культуру, выводя ее из под удара разрушающих внешних факторов, диктующих человеку определенное поведение, слова и даже мысли. Но русский человек не может мыслить по чьим-то образцам, он всегда свободен. Те моменты, когда русский человек вдруг бунтует $[14 ; 17 ; 20]$, это как раз и есть стремление к свободе, это борьба против хамства и все более давящих политических и социальных границ. Для западной культуры «важно отметить, что, исходя из принципов либеральной доктрины, понимание толерантности обосновывается с точки зрения рационализма. Так, в либерализме институциональные качества справедливости проявляют себя в законе и правосудии» [13, с. 318$]$. Правила социального и политического поведения чужды для русской культуры, потому как эти правила сформированы за пределами русского мира. «Но человек, принципиально и идейно оправдывающий свои неверные пути, лишает себя нравственного света и воздуха; он как бы угашает солнце над самим собою и в глубине своей собственной души и погружается в кромешную тьму, в которой зло и добро смешиваются; где именно поэтому нет ни зла ни добра, и душа начинает черстветь, чернеть и ожесточаться» $[8$, с. 416]. Поэтому в душе русского человека всегда светит нравственное солнце, делая его сильнее и оправдывая его поступки, придавая им смысл. «Душа, покорная хаосу, бессильна создавать космос во внешнем мире - в природе и общественности. Грубая и своевольная, жадная и упрямая, с порочными и разнузданными страстями, она бессильна создавать технику и организовывать хозяйство» [7, с. 446].

Современные либеральные тенденции в России основаны на раскрытии тех качеств, которые в русской культуре и сознании русского человека вызывают негодование. Продолжается поиск национальной идеи. Каждый русский человек сам решит, что ему делать, но он не может определиться без остальных, ему важно действовать в мире здравого смысла, в обществе, где он нашел бы отклик своим действиям. Пока же «проблема национальной идеи России, русская идея сегодня вновь волнует умы многих россиян. Споры о национальной идее останутся актуальными, по-видимому, до тех пор, пока наше Отечество не обретет тот путь, который поддержит большинство его граждан и который объединит их» [15, с. 31-32]. Многие современные реформы в нашей стране идут трудно, потому что они находят внутреннее сопротивление в душе конкретного человека. По словам А.А. Богданова, «начиная с эпохи Возрождения, великое освободительное движение человеческого духа шаг за шагом расчищает путь для непрерывного, беспрепятственного прогресса человеческих сил - индивидуальных и общественных... В сфере мышления эта освободительная работа выступает в форме критики, разбивающей бесчисленные фетиши, стоящие на пути познания, разрывающей бесчисленные путы, сковывающие его развитие» [3, c. 5]. В либерализме борьба за свободу оборачивается еще большим закрепощением. Человек стремится к личной свободе, стремится к себе, но и бежит он от себя. Получив политическую свободу, определенные политические права и социальные гарантии, человек в либерализме не останавливается на достигнутом, движется далее - сначала предлагает эти достижения другим народам и странам, a затем стремится к новым достижениям внутри своего общества. Это называется развитием. В действительности это всего лишь бегство, бегство от чего-то неведомого, непонятного, а если человек бежит от неведомого, то и путь, и цель его бегства тоже неведомы. Чтобы двигаться дальше, нужно отдавать отчет и понимать конечную цель своих действий. Либеральная западная толерант- 
ность, с которой столкнулась русская культуpa, конечной целью имеет либеральное освоение мира - навязывание правил жизни, где западные либерально настроенные деятели и есть главные изобретатели этих правил. «Европейская культура - это культура универсализма, при этом универсализма личностного характера. Личностный характер европейской культуры определяет ее особое отношение ко всему, находящемуся за пределами данной культуры. Это не только терпимость, но и в известной мере тяготение к другому» $[12$, c. 15]. Именно это тяготение к другому определяет основу либеральной толерантности, дающей права и свободы человеку, но при этом человек, сам того не понимая, становится заложником собственных представлений о демократии. Желая освободить от несвободы, либерализм ведет человека за собой, являясь как бы неким источником истины; человек воспринимает источником свободы именно то, что слышится ему не из уст Божественного, не из нравственного мира, а из мира свободы, созданного кем-то. Этот кто-то выходит прежде за рамки социальной организации, начинает управлять ею, а затем к этому управлению привлекает уже всех остальных людей, сам же уходит на еще более далекий уровень, оставляя так же определенные рамки несвободы, но это иные границы. Быть толерантным в этом смысле - значит допускать иные границы несвободы.

C позиций русской культуры толерантность стоит понимать как внутреннее, духовное качество, которое является в ней не чем иным, как смирением. Критика, по словам А.А. Богданова, - это преодоление внешних барьеров, но до каких пор человек будет преодолевать эти барьеры? Рано или поздно ему придется остановиться и задуматься над целями своих действий. Это характерно для западного либерализма. В русской культуре иное отношение к внешним факторам - русский человек не борется против внешних условий, с которыми он не согласен, но принимает их и обнимает всем сердцем. Иван Ильин в работе «О сопротивлении злу силою» писал: «...Борьба со злом есть процесс душевно-духовный; побеждает зло тот, кто превращает его в добро, то есть из глубины преображает духовную слепоту в духовную зрячесть, а силу каменеющей ненависти в благодатность приемлющей любви» [6, с. 347]. В русской культуре толерантность связана со всецелым овладением предметом, с его созерцанием. Созерцание - это понятие сакральное, связанное с глубоким, уважительным осмыслением в рамках нравственности и одухотворенности.

Еще один аспект толерантности в русской культуре - оценивание событий, поступков и действий. Оценка в русской культуре и русском менталитете не связана с осуждением и уничтожением. Почти всегда оценка поступков человека - это помощь ему согласно здравому смыслу. Соизмерение со здравым смыслом, определение отклонений от него. Толерантность - это не безоговорочное восприятие как есть, как получилось, а осмысление случившегося и недопущение возможных ошибок в будущем, а также добрый совет другим людям.

В настоящее время русский человек начинает оценивать события, пытаясь осмыслить происходящее, чтобы сориентироваться в нем. Но это осмысление не с целью получения прибыли и выгоды, это оценивание происходящего внутренним светом нравственности. Для русского человека очень важно, чтобы все было по совести, по-божески, чтобы действия не противоречили закону Вселенской гармонии. Сейчас в русском человеке просыпаются творческие силы и здравомыслие, он начинает понимать свою ответственность перед Родиной, родной землей, своим родом, семьей. Вместе с тем установки, образцы поведения уже не связаны с конкретными людьми, героями, кумирами и т. д. Образцы поведения нужно создавать самостоятельно, искать их, обратившись к познанию своей культуры. Это не просто тенденция российского общества, это черта планетарная. «В середине XX в. изменился характер авторитета; это уже не явный, а анонимный, невидимый, отчужденный авторитет. Требование не исходит ни от личности, ни из идеи, ни из нравственного закона... Действительно, нет другого авторитета кроме безликого "Нечто"» $[19$, с. 170]. Поддержки требовать не от кого, искать ее только в себе. Ждать, что кто-то сделает нас лучше и обеспечит наше существование, уже не просто бесполезно, а не имеет смысла. Русский человек должен не- 
сти ответственность за свою деятельность, а не отсылать к тому, что его кто-то заставил. Сейчас потенциал толерантности в русской культуре, проявляемый в истинном смирении, то есть в «бытии в мире», существовании «с миром», раскрывается с новой силой.

Темное начало приобретает божественные формы, безликая деятельность становится целенаправленной, обретает смыслы и конечные цели. «Стоит обратить внимание на тот факт, что за последние сто лет идеология консервативной революции принципиальных изменений не претерпела. Ее врагами, как и прежде, остаются либеральная модернизация, эгалитарная демократия, тотальная эмансипация» [1, с. 124]. Именно внешняя либеральная оболочка делает деятельность русского человека темной и бесцельной, отсталой, если угодно, западной культурой. Это не из-за отсутствия ума и творческих способностей русский человек не может организовать правовое государство и рыночную экономику, а от того, что эти образцы рынка и государства противоречат самой русской культуре, русскому духу. Тут обвинение в нетолерантности совсем не к месту, напротив - это и есть настоящая толерантность, в основе которой лежит смирение.

Толерантность русской культуры - прежде понимание, а затем определение. Эти оценки событий дает русский человек, он не в силах удержаться от суждений об увиденном. Русский человек любит посплетничать, порассуждать, высказать свое мнение по поводу тех или иных событий. Ему непременно хочется самому принять самое непосредственное участие в обсуждаемом событии. По этому поводу М.Н. Ефименко в статье «Отечественная философия о сущности и формах толерантности и особенностях русской религиозности» пишет: «Одно из проявлений ненасилия заключается в том, что человек не должен выступать судьей в вопросах жизни и смерти, поскольку это не его компетенция. В остальных случаях он может выступать судьей поступков людей, но при этом ни в коей мере не покушаться на их свободу» [5, с. 7]. Ненасилие значит словесное обсуждение, порицание без прямого вмешательства в то или иное жизненное обстоятельство.

Русская толерантность тесно связана с понятием справедливости. «Справедливость фиксирует приемлемую для нравственного сознания меру (порядок, способ, версию, тип) конфигурации социокультурной реальности. Если выразиться максимально кратко, то справедливость есть мера должного распределения благ и тягот» [9, с. 43]. Если что-то сделано несправедливо и кто-то поступил не по совести, то ни о какой толерантности не будет и речи в русском сознании. Справедливость - это непременное условие лояльного отношения русского характера ко всему происходящему. В этом случае толерантность обретает оттенок значимости. Трудно представить русскую культуру, которая шла бы на уступки и уступала бы полностью право на истину какой-либо идее, если она с этой идеей не согласна. Это касается сферы правовых отношений. Трудно заставить русского человека следовать правовым нормам, которые противоречат его здравому смыслу и пониманию жизни. Вся законная обязательность в русском мышлении носит формальный, внешний характер. Это касается и других сфер жизни русского человека - социальной, политической, экономической и др. Что касается сферы природы и культуры, то именно они признаются истинными и справедливыми в силу своей первозданности. Ожидание справедливости социальной и политической, правовой и экономической основано на культуре и подкрепляется природой. Природа становится первой жертвой несправедливости - вырубаются леса и выкачивается нефть, родная земля становится сырьевым придатком для внешнего мира. Русская природа принимает на себя первый удар либеральной идеи потребительства, впрочем, как и природа любой другой страны. Затратное отношение к природе в русском менталитете объясняется тем, что природные богатства не желают стать товаром и предпочитают погибнуть на родной земле. Данная идея вполне заслуживает внимания, потому как на практике мы имеем дело с многочисленными издержками природопользования в России. Но если распределить природные блага по совести, по справедливости, то русский человек станет первым заступником и хранителем родной природы.

Сейчас под воздействием внешних условий (экономических, социальных, политических, психологических и иных факторов) есть 
возможность изменять менталитет, влиять на русскую культуру. Данные факторы имеют весьма важное значение для формирования менталитета. Однако экономика, социальная и политическая сферы зависят от менталитета народа, его культуры. В настоящее время все больше в ученой среде понимающих то, что изменение внешних условий способствует определенному поведению человека в этих условиях. Бытие определяет сознание. Сначала закладывается привычка, а затем целая ментальная установка, встраиваемая в культуру. Скажем, развитие рыночных отношений наполнило наши прилавки различными товарами, человек оказался в ситуации, когда можно говорить о культуре потребления и формировать ее, дабы оградить людей от безудержного приобретения нужного и ненужного. Если говорить о личных взаимоотношениях, то они также связаны с ориентацией на рынок, то есть имеют психологической основой ожидание награды, однако «в личностно-культурном плане проблема толерантности "снимается” в виде выделения и описания ее как социокультурной нормы и морального принципа. В настоящее время проблематика толерантности образует состав этики ненасилия... Ненасильственный и толерантный мотив полагает воспринимать другого как равнодостойного участника и субъекта в общении. Одномерность человека и есть его крайняя нетолерантность, часто приводящая его к негативной (деструктивной) толерантности» [10, c. 333]. Русская толерантность не одномерная, она широка в своих проявлениях. Русский человек простит все, но если прощеный не будет жить по совести, то русский характер непременно вмешается. В либерализме это вмешательство называется нетерпимостью, несдержанностью, но в русской культуре это называется устроением жизни по совести.

В настоящее время открыты новые характеристики толерантности, глубже изучена психология этого понятия. В либеральной традиции мы видим непонятное разнообразие, связанное с нетрадиционными половыми ориентациями, однополыми браками и т. д. Русское мировоззрение не может это воспринять как норму. В русском православном (правильном) сознании это бесчинство, блуд. Если человек не следует своему чину - мужскому или женскому - значит он бесчинствует. А блуд всегда осуждаем. Блуд - это изнанка любви, ее суррогат. Любовь просыпается в человеке естественным образом, ее можно сломать, исказить, подменить, но нельзя уничтожить совсем. Тертий Филиппов в работе «Русское воспитание» говорит о чувстве любви следующее: «Не тот высоко ценит чувство любви, кто боится пронести жизнь, не испытав ее наслаждений, но тот, кто принимает счастье лишь тогда, когда оно не входит в раздор с высшими требованиями нравственного закона, кто отказывается от своих прав на счастье, боясь оскорбить святыню самого чувства какой-либо порочной примесью или постыдным торгом с совестью» [18, с. 89]. Но далее он продолжает: «Кроме того, что любовь чувство законное, но все-таки личное, - должна бывает иногда посторониться и дать дорогу другим побуждениям, но даже и в тех случаях, когда ее стремления не встречают никаких нравственных препятствий, не должно брать ее только с одной стороны ее значения, то есть только как источник личного счастья и наслаждения: у нее есть более важные стороны» [18, с. 89]. Любовь, как свойство и проявление толерантности русской культуры, это не только личное человеческое чувство, а чувство, имеющее общественную и культурную пользу - создание семьи, продолжение рода. Любовь - это прощение, но до определенного времени, поэтому русский долго терпит, прощает и потом начинает все переделывать, как должно было быть изначально. Но если это не получилось в жизни, стоит это отпустить. Не полученный в свое время социальный статус - это ничто из-за ситуации депривации, а вот поломанная совесть - это очень важно, стоит ее беречь, как и беречь любовь как личное, культурное и социальное богатство и мерило.

Человек всегда стремится обеспечить лучшую жизнь не только для себя, но и для всех остальных. «Не оформлен русский характер, недооформлен русский человек... Веками травили душу чужим снытьем, а в душу, в ее глубины, так и не проникли... Настоящему русскому, коренному и простому, в высшей степени присуща духовная черта, которую Солоневич назвал “совестливость". Именно так: не совесть, а совестливость» $[11$, с. 41-42]. О со- 
вестливости идет речь, когда русский человек выступает инициатором безвозмездной помощи, отдавая другим свое время и силы, желая отблагодарить Бога за то, что кто-то когда-то помог ему самому. Русская совесть, совестливость глубоко проникает в жизнь, связывая человека с миром. Совестливость сопутствует в русском менталитете естественным образом поступкам человека. Совестливости учить не нужно, она уже в русской культуре присутствует. Русский человек строит электростанции, фабрики и заводы по миру, помогает другим вместо того, чтобы наживаться трудом других стран и народов. Возможно, в этом есть свои корыстные интересы, но они ничуть не больше, чем оказываемая помощь.

Таким образом, толерантность русской культуры носит весьма разнообразные оттенки, связанные с различными понятиями. Эти понятия - естественное свойство русской культуры. Русская культура создана на русской земле, связана с ней. Многообразие факторов русской толерантности связано с природой. Природа определяет широту русской души и совесть человека, а совесть определяет поведение в социуме и в целом мире. Совестливость является социальным проявлением русской культуры. Русская культура дает свой ответ на вызовы западной толерантности, сохраняя свою целостность. Изучение аспектов толерантности в русской культуре позволило определить новые грани этого популярного современного понятия.

\section{СПИСОК ЛИТЕРАТУРЫ}

1. Бенедиктов, К. Консервативная революция и Традиция / К. Бенедиктов // Традиция и русская цивилизация / К. Бенедиктов, Д. Володихин, С. Алексеев, Н. Иртенина. - М. : Астрель : АCT : Транзиткнига, 2006. - 282 с.

2. Бердяев, Н. А. Судьба России. Опыты по психологии войны и национальности / Н. А. Бердяев. - М. : Мысль, 1990. - 208 с.

3. Богданов, А. А. Эмпириомонизм. Статьи по философии / А. А. Богданов. - М. : Книговек, 2014. -544 c.

4. Галимов, Б. С. Философия толерантности / Б. С. Галимов, А. А. Газетдинова // Вестник Башкирского университета. - 2015.-Т. 20, №3. -С. 1080-1082.

5. Ефименко, М. Н. Отечественная философия о сущности и формах толерантности и особен- ностях русской религиозности / М. Н. Ефименко // Вестник Оренбургского государственного педагогического университета. - 2008. - № 1. - С. 4-10.

6. Ильин, И. А. О сопротивлении злу силою / И. А. Ильин // Путь духовного обновления. Работы разных лет / И. А. Ильин. - СПб. : Библиополис, 2008. $-448 \mathrm{c}$.

7. Ильин, И. А. Собрание сочинений: Статьи. Лекции. Выступления. Рецензии (1906-1954) / И. А. Ильин. - М. : Рус. кн., 2001. -560 с.

8. Ильин, И. А. Учение о компромиссе и дурных средствах / И. А. Ильин // Собрание сочинений: Справедливость или равенство? / И. А. Ильин. - М. : ПСТГУ, 2006. - С. 415-444.

9. Карчагин, Е. В. Об идее справедливости в русской культуре / Е. И. Карчагин // Вестник Волгоградского государственного университета. Серия 7, Философия. Социология и социальные технологии. - 2016. - № 2 (32). - С. 42-48. - DOI: https://doi.org/10.15688/jvolsu7.2016.2.5.

10. Клейберг, Ю. А. Толерантность и деструктивная толерантность: понятие, подходы, типология, характеристика / Ю. А. Клейберг // Общество и право. -2012. - № 4 (41). - С. 329-334.

11. Колесов, В. В. Русская душа / В. В. Колесов // Общество. Среда. Развитие. - 2008. - № 1.- С. 31-47.

12. Лихачев, Д. С. Три основы европейской культуры и русский исторический опыт / Д. С. Лихачев // Наше Наследие. - 1991. - № 6. - С. 15-16.

13. Назарова, Ю. В. Философия политической толерантности в либерализме / Ю. В. Назарова // Научные ведомости Белгородского государственного университета. Серия «Философия. Социология. Право». - 2013. - № 24. - С. 312-320.

14. Подоксенов, А. М. Русский бунт. Версия Михаила Пришвина / А. М. Подоксенов // Человек. -2012. - № 4. - С. 120-133.

15. Полежаев, Д. В. Российская идентичность в исторической динамике: ментальные аспекты исследования / Д. В. Полежаев // Primo Aspectu. 2015. - Т. 20, № 2 (155). - С. 29-34.

16. Сабиров, А. Г. Толерантность как свойство русского человека / А. Г. Сабиров // Теория и практика толерантности: этнокультурные и межконфессиональные аспекты : материалы Всерос. науч.практ. конф., г. Нижнекамск, 5 дек. 2008 г. / отв. ред. О. Д. Агапов. - Казань : Познание, 2009. - 380 с.

17. Тамарченко, Н. Д. Русский бунт у Пушкина и Достоевского («Капитанская дочка» и «Бесы») / Н. Д. Тамарченко // Новый филологический вестник. -2009. - № 4 (11). - С. 18-24.

18. Филиппов, Т. И. Русское воспитание / Т. И. Филиппов. - М. : Ин-т рус. цивилизации, 2008. -448 c.

19. Фромм, Э. Здоровое общество / Э. Фромм. M. : ACT, 2015. $-448 \mathrm{c}$. 
20. Karlova, O. A. The mindset of Russian poetry and its rebellion against Russian history / O. A. Karlova // Журнал Сибирского федерального университета. Серия «Гуманитарные науки». 2016. - Т. 9, № 2. - С. 358-373.

\section{REFERENCES}

1. Benediktov K. Konservativnaya revolyutsiya i Traditsiya [Conservative Revolution and Tradition]. Volodikhin D. et al., eds. Traditsiya $i$ russkaya tsivilizatsiya [Tradition and Russian Civilization]. Moscow, Astrel Publ.; AST Tranzitkniga Publ., 2006. 282 p.

2. Berdyaev N.A. Sudba Rossii. Opyty po psikhologii voyny i natsionalnosti [The Fate of Russia. Experiments on the Psychology of War and Nationality]. Moscow, Mysl Publ., 1990. 208 p.

3. Bogdanov A.A. Empiriomonizm: Statyi po filosofii [Empiriomonism: Articles on Philosophy]. Moscow, Knigovek Publ., 2014. 544 p.

4. Galimov B.S., Gazetdinova A.A. Filosofiya tolerantnosti [Philosophy of Tolerance]. Vestnik Bashkirskogo universiteta, 2015, vol. 20, no. 3, pp. 1080-1082.

5. Efimenko M.N. Otechestvennaya filosofiya o sushchnosti i formakh tolerantnosti i osobennostyakh russkoy religioznosti [Russian Philosophy about the Nature and Forms of Tolerance and Peculiarities of Russian Religiosity]. Vestnik Orenburgskogo gosudarstvennogo pedagogicheskogo universiteta, 2008, no. 1, pp. 4-10.

6. Ilyin I.A. O soprotivlenii zlu siloyu [On the Force Resistance to Evil]. Put dukhovnogo obnovleniya. Raboty raznykh let [The Way of Spiritual Updates. Works of Different Years]. Saint Petersburg, Bibliopolis Publ., 2008. 448 p.

7. Ilyin I.A. Sobranie sochineniy: Statyi. Lektsii. Vystupleniya. Retsenzii (1906-1954) [Collected Works: Articles. Lectures. Presentations. Reviews (1906-1954)]. Moscow, Russkaya kniga Publ., 2001. 560 p.

8. Ilyin I.A. Uchenie o kompromisse i durnykh sredstvakh [The Doctrine on Compromise and Bad Media]. Sobranie sochineniy: Spravedlivost ili ravenstvo? [Collected Works: Justice or Equality?]. Moscow, PSTGU, 2006, pp. 415-444.

9. Karchagin E.V. Ob idee spravedlivosti v russkoy kulture [The Idea of Justice in the Russian Culture]. Vestnik Volgogradskogo gosudarstvennogo universiteta. Seriya 7, Filosofiya. Sotsiologiya $i$ sotsialnye tekhnologii [Science Journal of Volgograd State University. Philosophy. Sociology and Social Technologies], 2016, no. 2 (32), pp. 42-48. DOI: https:// doi.org/10.15688/jvolsu7.2016.2.5.
10. Kleyberg Yu.A. Tolerantnost i destruktivnaya tolerantnost: ponyatie, podkhody, tipologiya, kharakteristika [Tolerance and Destructive Tolerance: Concept, Approaches, Typology, Characteristics]. Obshchestvo i pravo, 2012, no. 4 (41), pp. 329-334.

11. Kolesov V.V. Russkaya dusha [Russian Soul]. Obshchestvo. Sreda. Razvitie, 2008, no. 1, pp. 31-47.

12. Likhachev D.S. Tri osnovy evropeyskoy kultury i russkiy istoricheskiy opyt [Three Foundations of European Culture and the Russian Historical Experience]. Nashe nasledie, 1991, no. 6, pp. 15-16.

13. Nazarova Yu.V. Filosofiya politicheskoy tolerantnosti v liberalizme [The Philosophy of Political Tolerance in Liberalism]. Nauchnye vedomosti Belgorodskogo gosudarstvennogo universiteta. Seriya "Filosofiya. Sotsiologiya. Pravo", 2013, no. 24, pp. 312-320.

14. Podoksenov A.M. Russkiy bunt. Versiya Mikhaila Prishvina [Russian Riot. Version of Mikhail Prishvin]. Chelovek, 2012, no. 4, pp. 120-133.

15. Polezhaev D.V. Rossiyskaya identichnost v istoricheskoy dinamike: mentalnye aspekty issledovaniya [Russian Identity in the Historical Dynamics: the Mental Aspects of the Research]. Primo Aspectu, 2015, vol. 20, no. 2 (155), pp. 29-34.

16. Sabirov A.G. Tolerantnost kak svoystvo russkogo cheloveka [Tolerance as a Russian Trait]. Agapov O.D., ed. Teoriya i praktika tolerantnosti: etnokulturnye i mezhkonfessionalnye aspekty: materialy Vserossiyskoy nauchno-prakticheskoy konferentsii, g. Nizhnekamsk, 5 dekabrya 2008 g. [Theory and Practice of Tolerance: Ethnocultural and Interconfessional Aspects: Proceedings of the AllRussian Scientific and Practical Conference, Nizhnekamsk, December 5, 2008]. Kazan, Poznanie Publ., 2009. 380 p.

17. Tamarchenko N.D. Russkiy bunt u Pushkina i Dostoevskogo («Kapitanskaya dochka» i «Besy») [Russian Riot Depicted by A.S. Pushkin and F.M. Dostoevsky (The Captain's Daughter and Demons)]. Novyy filologicheskiy vestnik, 2009, no. 4 (11), pp. 18-24.

18. Filippov T.I. Russkoe vospitanie [Russian Education]. Moscow, In-t russkoy tsivilizatsii, 2008. $448 \mathrm{p}$.

19. Fromm E. Zdorovoe obshchestvo [A Healthy Society]. Moscow, AST Publ., 2015. 448 p.

20. Karlova O.A. The Mindset of Russian Poetry and Its Rebellion Against Russian History. Zhurnal Sibirskogo federalnogo universiteta. Seriya "Gumanitarnye nauki", 2016, vol. 9, no. 2, pp. 358-373. 


\section{Information About the Author}

Aleksandr G. Ilyin, Candidate of Philosophical Sciences, Associate Professor, Department of Philosophy and Sociology, Elabuga Institute of Kazan (Volga Region) Federal University, Kazanskaya St., 89, 423604 Elabuga, Russian Federation, sashailin@mail.ru.

\section{Информация об авторе}

Александр Геннадьевич Ильин, кандидат философских наук, доцент кафедры философии и социологии, Елабужский институт Казанского (Приволжского) федерального университета, ул. Казанская, 89, 423604 г. Елабуга, Российская Федерация, sashailin@mail.ru. 